\title{
Designing a Global Digital Currency
}

\author{
Ronald J. Balvers \\ DeGroote School of Business \\ McMaster University \\ Hamilton, ON L8S 4M4 Canada \\ $905.525 .9140 \times 23969$ voice \\ balvers@mcmaster.ca
}

\author{
Bill McDonald \\ Mendoza College of Business \\ University of Notre Dame \\ Notre Dame, IN 46556-5646 \\ 574.631 .5137 voice \\ mcdonald.1@nd.edu
}

October 6, 2017

\begin{abstract}
The notion of a global currency is a debate set aside in the past decade as the abstraction saw little potential for realization in a world with heterogeneous governments unwilling to sacrifice seigniorage for optimal design. The technical capability of creating digital currencies, independent of governments, resurrects the discussion and begs the questions of practical design and implementation. We discuss the characteristics of an ideal global currency and consider empirically the factors a cryptocurrency might use to create a portfolio mimicking the ideal design.
\end{abstract}

Keywords: Global currencies; digital currencies; cryptocurrencies; currency design; Bitcoin

JEL Codes: E4; E42, E31; F3382; D83; G14; G18; G30; M40; M41

We thank Paul Gao, Martijn Cremers, Margie Forester and Jeff Bergstrand for helpful comments. 


\section{Introduction}

Arguably the most ubiquitous yet least understood of human innovations is money. Money, in some form, is nearly as old as the exchange of goods and services, and its long history has been well documented. ${ }^{1}$ In the past century, fiat money-currency not backed by physical commodity and deemed by the government to be legal tender-along with bank money, have become the predominant forms of what is considered money in today's central market economies.

Governments, in modern history, play a singular role in the distribution and regulation of money. With the shift from nationalism toward globalism, motivated by international trade, the notion of a global currency received considerable attention in the past few decades. Figure 1 presents the percentage of the phrase "global currency" used in books over the years 1940 to 2008 taken from Google’s n-gram viewer. ${ }^{2}$ The figure clearly documents the topic’s rising popularity in the 1990's - no doubt fueled by the successful introduction of the Euro-and its post-2000 plateau. Rogoff (2001) presents what might be labeled as the obituary for this discussion of global currencies, where the ideal of a global currency is confronted with the reality of governments that have no incentive to create a truly universal and stable numeraire.

The constraints on designing a global currency, created by the monopoly governments have on the production of money and the lack of incentives these governments have to sacrifice seigniorage for stability, have been disrupted by the potential of digital currencies, also known, based on their underlying technology, as cryptocurrencies. New digital coins in the form of initial coin offerings (ICOs) are being created on a regular basis, with more than thirty scheduled in May of $2017 .^{3}$

Given the ability to now create currencies within blockchain platforms, we will focus in the current paper on the ideal design of a global currency and its implementation. Simply put, ignoring regulatory and political constraints, an ideal currency will be stable in terms of purchasing power. We discuss the issues associated with achieving this ideal and argue that one of the first implementation hurdles is identifying a continuous and verifiable measure of general inflation. ${ }^{4}$

\footnotetext{
${ }^{1}$ See, for example, Davies (2002).

${ }^{2}$ https://books.google.com/ngrams/info. The n-gram viewer is based on text from over five million books and is available through 2008.

3 https://www.smithandcrown.com/icos/.

${ }^{4}$ We will use the term "continuous measurement" in this paper when referring to values available in market time, i.e., periods when markets trade.
} 
Lack of continuous inflation measurement in practice contributes to possible shortfalls in guaranteeing stable purchasing power, which we show is equivalent to the value of writing a put option on the purchasing power measure. Fluctuations in the value of this put option interfere with the stability of the ideal currency but will be limited by integrating continuous inflation forecasts. Given these theoretical results, we then focus on empirically identifying continuously tradable assets that might serve to create a mimicking portfolio for inflation.

Our paper differs from the rich history of literature on global currencies because the tenor of the discussion has changed significantly with the disruptive technology of digital currencies. The discussion of global currencies is very different in a new world where non-country specific currencies can be created in software. In this case, quantities may be verifiably limited, small fees or payoffs may be imposed without significant transaction costs, target values may be enforced transparently, and political influences are absent. As opposed to traditional designs, the design of the ideal currency may rely on perfect pre-commitment to a particular inflation measure. It may include a transparent structure of continuous fees and may be spent frictionlessly. Payoffs to stabilize purchasing power may be guaranteed mechanically by collateral held in escrow. Stable real payoffs in the interim between official price level measurements, however, compel continuous inflation forecasts to mitigate possible collateral shortfalls.

Our empirical work differs from the prior attempts to forecast or hedge inflation such as Ang et al. (2007), Ang (2014, Chapter 11), or Stock and Watson (2005) because of our focus on continuous measurement, prediction with contemporaneous variables, and verifiability.

The rest of the paper is organized as follows. Section 2 discusses the characteristics of an ideal currency in contrast to traditional currencies and outlines some of the initial attempts to implement stable digital currencies. In Section 3 we provide a theoretical framework for an ideal currency and discuss some of the associated issues of markets, risk and seigniorage. A theoretical model of a stable global currency is derived in Section 4. We consider models for creating a continuously measured proxy for inflation using data from 2004-2016 in Section 5. Section 6 concludes. 


\section{The ideal global currency}

\subsection{Purchasing power stability of traditional currencies}

The discussion of money can be framed using the traditional M0-M4 labels, a common lexicon across countries' monetary authorities (although sometimes not defined in exactly the same terms), or, more generally, we can think of money as a subset of what Gorton (2017) labels as "safe assets".

Historically, however, no type of money has always been a safe and reliable asset. Commodity monies were subject to changes in the value of the commodity, counterfeiting and debasement, as well as shortages (see for instance Sargent and Velde, 2002). Most fiat monies have periodically been subject to significant inflation, often the result of governments using the printing press as a politically convenient method of taxation. While in some countries indexed bonds have been available, providing some protection against inflation, such indexed bonds have not been negotiable and no examples exist where these bonds have been used for transaction purposes.

In the current era, inflation has been low and not highly variable, at least in a large group of developed economies. However, in light of historical experience, there is no basis for believing that the regime of moderate and predictable inflation will persist. Hence, the absence of money that is safe in terms of guaranteeing holders stable purchasing power is significant and is responsible for a variable but ever-present tax on transactions.

Attempts at creating a world currency, in particular via the International Money Fund's creation of Special Drawing Rights (SDR's), have not been a conspicuous success. In part, the reason is that even if SDR's helped to even out differences in purchasing power parity across countries, they would not guarantee low inflation. For instance, there is no reason that baskets of goods around the world could not all be more expensive in units of SDR's. Thus, SDR's, even if universally accepted as a medium of exchange, would not automatically protect the purchasing power of their consumers. As a thought experiment, imagine a world-wide inflation rate of $10 \%$. As a basket of currencies measured relative to other currencies, the SDR's value would not change.

Even if, miraculously, governments around the world could coordinate their policies in such a way as to uniformly target low inflation, the sticky question of whose inflation should be targeted remains. Unless all relative prices of goods and services are constant, stable purchasing power for any individual is specific to the basket of goods that the individual consumes. The typical basket of goods varies by country, but even within a country varies by age, sex, location (urban or rural), and other demographics. 
A further impediment to creating a global currency with stable purchasing power is related to measurement. Specifically, governments are usually responsible for collecting prices to construct a price index and measure the inflation rate that would be used in stabilizing the purchasing power of an ideal currency. But these same governments may also have political incentives to overstate or understate inflation providing, in the absence of an objective oracle, a possible inducement for incorrect measurement.

\subsection{Digital currencies attempting stability and their limitations.}

The desirable aspects of a global currency that is (1) stable, and accordingly, serving well as a store of value and as a unit of account and (2) an efficient medium of exchange (portable, low transactions cost, homogeneous, infinitely divisible), may in principle be realized by digital currencies and quite easily on the Ethereum platform. The Ethereum platform provides a Turingcomplete language (Turing 1937) for building smart contracts that facilitates the creation of new cryptocurrencies. Although Bitcoin was the pioneer of blockchain-based digital currencies, the flexibility of the Ethereum platform provides a fertile environment for the development of new

currencies. ${ }^{5}$ We review some of the extant discussions on creating stable digital currencies in the following paragraphs.

A blog post by Vitalik Buterin, founder of Ethereum, provides a useful summary of the search for a stable cryptocurrency. ${ }^{6}$ He distinguishes two classes of solutions for measuring the price that the currency targets: exogenous and endogenous. We will mostly consider exogenous solutions that rely on an outside oracle or outside voters to provide the targeted value of the currency. Endogenous solutions rely on variables internal to the network to measure the targeted currency value.

Schellingcoin provides one example of an exogenous solution for the price measurement system. This system works by letting stakeholders in the system (based on proof of work or proof of stake) vote on the target currency value, with rewards for voters based on the closeness to the consensus. Voters then have an incentive to provide their best forecast. Buterin points out possible

\footnotetext{
${ }^{5}$ For recent reviews of blockchain-based technologies in finance see Huberman et al. (2017), Cong and He (2017), Yermack (2017), or Harvey (2016).

${ }^{6}$ “The Search for a Stable Cryptocurrency,” November, 2014, https://blog.ethereum.org/2014/11/11/search-stablecryptocurrency/.
} 
destabilizing games that may be played when some voter pre-announces an (incorrect) target value that would benefit a substantial subgroup of voters.

Endogenous solutions to the price measurement system involve services inside the network that have reasonably stable real values. For instance, transaction fees or the difficulty of mining. Tying a currency to such variables would remove some risk but not those risks related to technological innovation. Buterin shows that some of these network service measures when adjusted for various trends have tracked bitcoin values quite well, cancelling out more than 50\% of cryptocurrency price volatility. A potential problem is that certain network service measures, such as transaction costs may be manipulated to affect price measurement.

Stable currency may be issued as mining rewards, and more so if the price is higher (relative to target). However, since mining rewards cannot be negative it is difficult to reduce the quantity of currency if the price is lower than target. In practice, most ideas for a stable currency avoid this problem by introducing two sides to a coin: volatilecoins (vol-coins) and stablecoins.

Buterin discusses various stable currency proposals based on the two-sided coin idea:

1. BitAssets: Stablecoins have by definition a value of $\$ 1$ and are in zero net supply. A negative value in stable coins is a debt and requires a collateral in vol-coins that is, say, \$2 per stablecoin. If the collateral goes down to, say, $\$ 1.05$ per stablecoin the debt is cancelled and the debt-holder receives the remaining collateral.

2. SchellingDollars: Only holders of vol-coins may issue (hold negative values of) stablecoins (up to $50 \%$ of vol-coin value). If the vol-coins collateral decreases to, say, $105 \%$ of outstanding stablecoins, the balance of both is reduced to zero. Vol-coins may always be exchanged for stablecoins and vice versa at the rate of $\$ 1$ for a stable coin (possibly at a small transaction fee). The aggregate quantity of stablecoins (which may be negative) determines the interest rate for holding stablecoins according to some pre-set rule.

A more recent currency proposal not discussed in Buterin's 2014 blog post concerns the Dai stablecoin proposal by the Maker DAO (Digital Autonomous Organization). Here the stablecoins are not in zero net supply but are created by any currency “maker” who locks up a number of ether coins worth $1+c$ SDRs which allows issuance of one stablecoin and one vol-coin. Upon maturity, the stablecoin receives one SDR and the vol-coin the remainder.

A blog post by Kenny Rowe discusses the stability of the system and simulates the feedback mechanism used for stabilizing the Dai stablecoin at a target price by varying the fee (the "deflation 
rate”) based on deviations of market price from target price. ${ }^{7}$ He emphasizes the importance of modeling market behavior in order to better design the feedback control system that prices the currency.

In July of 2017, coinmarketcap.com listed 1,138 digital currencies, with 62 having market capitalizations greater than $\$ 100$ million. Only a few of these currencies are focused on creating a stable currency, and even among those, the stablecoin offerings to date have not focused on the general notion of an ideal global currency, but more on creating a currency that is not subject to the extraordinary volatility seen in both bitcoin and ether. For example, in a three-month period in 2017, bitcoin surged more than 220\% from $\$ 935$ (per BTC) to more than $\$ 3,000$, then quickly fell below $\$ 2,000$. Over the same period, ETH (Ethereum's ether) went from around $\$ 40$ to over $\$ 400$ and then fell below $\$ 130$. Most current attempts at stability focus on anchors such as the U.S. dollar or price of gold. Bitshares' SmartCoins and Nu's Nubits anchor to the dollar. Digix's DGX is anchored in gold and more recently Maker's Dai is targeted to SDR's. The creation of stable digital currencies obviously begs the question of stable relative to what? Stabilizing relative to inflation, although potentially more difficult, takes a substantial step toward an ideal solution.

Even within the digital world, there is a demand for stable currencies. For example, Augur provides a decentralized prediction market built on the Ethereum blockchain. If you take a financial position based on an election outcome, you do not want your payoff to be exposed to both the fundamental risk along with a (large) currency risk.

Although anchoring in the U.S. dollar would provide a currency far less volatile than the two major digital currencies (BTC and ETH, at this time), it does not resolve the most fundamental issue of today's fiat currencies - inflation. Below we sketch an example of a currency that may be created digitally and moves in the direction of an optimal design. The example is a simplified version, with a few significant alterations, of stable currencies that are already being developed (most similar to Maker's Dai stablecoin proposal). However, we are not solely concerned with stability in nominal terms (against the dollar or SDR), which is more straightforward because price observations are available nearly continuously, but also with stability in real terms, which results in a price level target that is observed infrequently (typically on a monthly basis). We also avoid

\footnotetext{
7 "Digital Money: A Simulation of the Deflation Rate Adjustment Mechanism of the Dai Stablecoin,” August, 2016, https://steemit.com/makerdao/@kennyrowe/digital-money-a-simulation-of-the-deflation-rate-adjustmentmechanism-of-the-dai-stablecoin.
} 
the stabilization issues that arise if a target price is maintained. In our model, the value of the stablecoin is guaranteed at the time of an oracle announcement based on a price index; at any other time, liquidity is based on market price. There is no need for a target price.

\section{A theoretical framework for designing a currency with stable purchasing power on the Ethereum platform}

The currency we propose may be viewed as a callable negotiable index bond with continuous coupon payments that is collateralized and has an indefinite maturity date. The coupon payments are renegotiated periodically but bondholders may convert the bond at any time for the value of the underlying index asset. The value of the underlying asset at each time is equal to the prevailing price of purchasing a particular defined basket of goods. The bond has no counterparty risk and, for consumers whose utility depends on the quantity consumed of the particular basket, this bond is truly risk free from period to period. In the long run, possible changes in the stream of coupon payments to be tendered imply a modest degree of risk.

The key ingredient in the design is to split ownership of digital currency (say ETH), which is inherently risky in nominal terms and has been highly volatile historically, into a nominal component that is illiquid and bears return risk, and a real component that is highly liquid and bears no return risk. Separation into these two components also makes it possible that, even though the risky component is heterogeneous (varies by remaining collateral and term to maturity), the riskless part is homogeneous (is independent of date of issue and other characteristics of the issue).

\subsection{Mechanics of a stable currency}

The platform allows periodic auctions to be held that may coincide with realizations of an oracle that generates the current rate (in numbers of ether) at which one unit of the stable currency can be exchanged.

For the auction, individuals desiring to purchase units of the stable currency provide: (a) the highest fee they are willing to pay; and, (b) the number of units requested at this or a lower fee. Of course, an individual may submit a whole menu of fee/unit combinations. Any such demands are only considered once they are backed by ether in escrow equal to the ether price per currency unit (based on the oracle) times the requested quantity. The escrow is automatically either returned 
after the auction if the auction-established fee is above the maximum set by the individual, or converted to the desired number of stable currency units at the auction-established fee.

Individuals wanting to redeem existing units of the currency also constitute a demand component: (a) the desired redemption in exchange for the underlying asset (the oracle-based price in ether of the asset per unit); (b) the automatic redemption if the collateral of a particular unit falls below a pre-set minimum at the realized oracle price; and, (c) conversion of maturing units.

Individuals electing to issue new units of the currency submit: (a) the lowest fee they are willing to accept; (b) the number of units to be issued at this or a higher fee; and (c) escrow in an amount of ether equal to the desired quantity times the ether cost of the basket of goods that is the target (based on the oracle) times $1+\mathrm{c}$, where $\mathrm{c}$ is the pre-set fraction of extra collateral required (for example, Maker proposes to set this amount to around 50\%).

The auction produces the quantity of new units (which may be negative) and the continuous fee to be charged until the next oracle/auction event, at which time all desired purchases, issues and redemptions are realized automatically.

Redemptions imply that the original issuers of a now redeemed unit receive their remaining collateral back. The return to the issuer depends on: (a) the fee over the duration of the unit's existence (the unit depreciates continuously at the fee rate); ${ }^{8}$ and, (b) variation of the cost of the underlying basket of goods in ether units. The issuer absorbs this risk so that the currency remains stable. Roughly, the percentage appreciation (likely to be negative in an inflationary environment) of the value of ether in terms of the real asset is the capital gains part of the issuer's return.

The coupon yield part of the issuer's return, an interest expense for the user of the stable currency consists of three components: (a) an inflation premium (included in the fee); (b) a risk premium of zero; and (c) a convenience yield for being able to use a truly risk free and liquid medium of exchange (the fee compensates issuers for time preference on the temporary loss of their principal plus added collateral).

\subsection{The secondary market}

In between auctions and oracle observations, a standard market exists for converting between ether and the stable currency. Both are homogeneous assets and the market should be liquid. The

\footnotetext{
${ }^{8}$ This constitutes the dividend/coupon component of the issuer's return. Only the undepreciated part is redeemed at the oracle price.
} 
value of the currency should be based on the anticipated oracle price but may deviate from it within fairly narrow bounds based on basic demand and supply considerations in the interim between oracle announcements of the targeted index.

While the stable currency unit is homogeneous, the issuer's rights to the remaining collateral that includes the return on the investment are not homogeneous. It is possible to create at the time of issue not only the stable currency unit, but at the same time an issuer token that represents the rights to the collateral upon maturity. Creating the issuer token is advantageous as it allows the issuer's investment to become negotiable and hence more liquid. It is not homogenous and its value is, aside from the fee and current oracle price, which are the same for all, dependent on: (a) the remaining collateral; (b) the time to maturity; and (c) the accumulated fees. Accordingly, the market for issuer tokens will be less liquid.

\subsection{Remaining risks}

\subsubsection{Jumps in ether's value relative to the underlying asset}

What happens if the collateral locked up for a particular stable currency unit becomes negative? Even if nominal ether values become less variable, auctions and oracle observations occur frequently, and the minimum fraction of collateral that triggers conversion is high (say 0.5c), it is possible that the collateral (for some of the currency units) has depreciated completely at the time of a required redemption at auction. For instance, at Auction t, $80 \%$ of the $0.5 \mathrm{c}$ collateral is left (1.40 times the unit value still available), but in the intervening period until Auction $t+1$, the ether has depreciated by $50 \%$ leaving only a share of 0.70 as collateral. Upon redemption, the Issuer receives nothing. The User receives the full value of 1.00 times the underlying asset. The missing $30 \%$ times the number of units involved must be taxed on the system. This occurs through a (small) post-hoc fee levied at the start of the auction on all current currency units. The extra fee cannot be avoided by redeeming the unit. This is important as it prevents 'bank runs' in terms of mass redemptions at the prospect of shortfalls.

By the system choosing dynamically its minimum collateral rate and by holding frequent auctions it should be possible to minimize the possibility of shortfalls to the point where it becomes inconsequential, especially in steady state when ether is expected to be reasonably stable. 
To minimize risk further, it is possible to involve additional oracles in the form of betweenauction observations of ether/stable currency exchange rates, allowing conversion immediately when collateral becomes too small.

\subsubsection{Liquidity risk}

The stable currency will only reach its proper real value at the time of the oracle's price release when it can be redeemed at the true cost of the underlying basket. This means that Users run a liquidity risk in the period between oracle observations. The option is to wait for the next observation or to trade in the secondary market. So long as pricing in the secondary market does not deviate too much from fundamentals, immediate liquidity may be obtained by accepting only a small capital risk.

\subsection{The intermediary role}

In our example, the Ethereum platform serves as an intermediary by pooling the currency so that the stable currency may be homogeneous, even if the issuer tokens are not. The role here is analogous to that of a depository institution providing heterogeneous loans while creating homogeneous deposits that may be used as a medium of exchange (and are typically included in money supply definitions). Of course, in contrast to cryptocurrencies, with depositary institutions there is counterparty risk in the sense that, without complete deposit insurance, a depository institution may fail so that deposits lose their value.

\subsection{What happens to the seigniorage?}

When we have commodity-based monies there is no seigniorage component: the difference between the market value and the issue cost is zero. In other words, the coverage ratio is $100 \%$. In principle, the same may seem to apply to the stable currency discussed here. In fact, as a currency fully backed by a real basket of goods it would have a $100 \%$ coverage ratio. Moreover, due to the collateral requirements there appears to be negative seigniorage as the coverage ratio is larger than $100 \%$, namely $(1+\mathrm{c}) * 100 \%$.

This perspective is incomplete, however, as it is a partial equilibrium one. Consider a steady state in which (fairly stable) cryptocurrencies are used in a substantial part of economy-wide transactions. Thus, in part they replace traditional fiat currencies. As the cryptocurrencies are 
pure fiat (they have a coverage ratio of $0 \%$ ), any creation of a cryptocurrency unit implies seigniorage equal to the market value of its increased supply minus the cost of "printing" the additional currency.

For every unit of stable currency created there is a cost of $(1+c) * 100 \%$ in units of ether so based on this by itself there is negative seigniorage for the stable currency addition. However, each of the $(1+c) * 100 \%$ units are locked up in escrow during the full life of the stable currency and thus, all else equal, require creation of this many units to maintain the transactions volume financed directly by ether. The seigniorage associated with this would be the cumulative interest on the full quantity of stable currency outstanding. To the extent that the stable currency replaces ether-based (or other cryptocurrency) transactions, the seigniorage is reduced. Thus, the seigniorage is the interest on the part of the supply of stable currency that replaces traditional currency.

There are two problems with this argument for a seigniorage related to the creation of a stable coin. First, the ether that is the escrow currency here has a pre-ordained fixed supply. Hence, the reduction in its available supply does not summon additional supply but instead may increase the price of the available units of ether. The resulting gain would technically not be called a seigniorage gain and would accrue to current holders of ether and not to a disembodied issuer. Second, the nature of many cryptocurrencies, and ether in particular, is that creation is costly beyond that of a simple printing cost. In equilibrium, expected mining costs would equal the expected value (price at issue) of ether. Hence, the value of the increased supply minus the cost of creating it would be expected to be zero. As new issues of ether are a competitive reward for the mining operations that verify transactions, the seigniorage may alternatively be viewed as financing part of the cost of running the system.

\section{A model of a stable global currency}

To examine the workings of a "two-sides-of-the-same-coin" stable currency built on the Ethereum platform that also preserves constant purchasing power, we first provide a simple stochastic formulation for the valuation of Ethereum coins and then consider the pricing implications for the 
two sides of the coin - the stable component (preserving purchasing power) and the volatile component.

\subsection{Valuing ether in simple terms}

All prices are presented in real terms. Thus, the (real) price of ether is

$$
p_{t}^{E} \equiv P_{t}^{E} / P_{t}
$$

The nominal "price” (exchange rate) of ether at time $t, P_{t}^{E}$, is expressed as the quantity of standard currency (dollars) per unit of ether $(\$ / E T H)$. The price level, $P_{t}$, reflects the cost of a basket of goods in dollar terms (\$/Good). Hence, $p_{t}^{E}$ is expressed as the number of baskets of goods one unit of ether can buy (Good/ETH). An increase in $p_{t}^{E}$ indicates an increase in the purchasing power of ether.

The value of ether lies in its use in regular digital transactions and as "gas" to fuel transactions on the Ethereum platform. Holding it reflects a convenience yield $x_{t}$ that evolves over time and which we model as a geometric Brownian motion. Continuous equilibrium pricing of ether implies:

$$
p_{t}^{E}=E_{t}\left[\left(\frac{m_{t+d t}}{m_{t}}\right) p_{t+d t}^{E}+x_{t} d t\right]
$$

Here $m_{t}$ is the equilibrium stochastic discount rate (pricing kernel). Over the infinitesimal period $d t$ the value of ether reflects its discounted future value plus the convenience yield. The convenience yield follows a zero-mean growth geometric Brownian motion process:

$$
d x_{t} / x_{t}=\sigma_{x} d z_{t}
$$

where $z_{t}$ is a standard Brownian motion process and $\sigma_{x}$ a constant volatility parameter. The stochastic discount factor is given exogenously as a geometric Brownian motion process with drift 
reflecting time preference and, to focus on the issues at hand, taking inflation risk as the only systematic risk in the economy, implies:

$$
d m_{t} / m_{t}=-r d t+\sigma_{m} d w_{t}
$$

The volatility parameter is $\sigma_{m}$ and $w_{t}$ is a standard Brownian motion process that is correlated with $z_{t}$ so that $E_{t}\left(d z_{t} d w_{t}\right)=\rho d t$. The drift in the discount factor represents the real interest rate $r$ which is assumed to be constant over time.

Given that the ether asset price follows a Martingale we have that

$$
d E_{t}\left(m_{t} p_{t}^{E}\right)=0
$$

Applying Ito’s lemma and equation (2) to equation (5),

$$
E_{t}\left[d p_{t}^{E}+x_{t} d t+p_{t}^{E}\left(d m_{t} / m_{t}\right)+\left(d p_{t}^{E}+x_{t} d t\right)\left(\left(d m_{t} / m_{t}\right)\right]=0\right.
$$

To solve for the equilibrium price of ether, we guess and verify that $p_{t}^{E}=A x_{t}$, where $A$ is an as yet undetermined constant coefficient. Given the guess, and using equations (3) and (4), equation (6) becomes $x_{t} d t-r p_{t}^{E} d t+\rho \sigma_{x} \sigma_{m} A x_{t} d t=0$. Hence,

$$
p_{t}^{E}=\frac{x_{t}}{r-\rho \sigma_{x} \sigma_{m}}
$$

Equation (7) provides the equilibrium price of ether and verifies the guess that it is a constant proportional to the convenience yield $x_{t}$. The denominator represents the perpetual required return (opportunity cost) for holding ether: the real interest rate plus a term that reflects the inflation risk premium. The risk premium is positive if $\rho<0$. In this case, an increase in the convenience yield is negatively correlated with an increase in the stochastic discount rate. This means that the value of ether is higher when the market values it less. In effect, higher inflation (increasing the stochastic 
discount rate) lowers the real value of ether (if $\rho<0$ ) so that it contains systematic inflation risk which makes it less valuable. In practice, we expect ether to correlate imperfectly in nominal terms with the price levels, which means it falls in real terms as the price level rises. However, ether (together with its convenience yield $x_{t}$ ) will generally move significantly for many reasons unrelated to the business cycle in general and inflation in particular. Thus, it is reasonable to assume that, in practice, although $\rho<0$ it is small in absolute value. Naturally, if $\rho>0$, ether would be an inflation hedge and its risk premium would be negative.

In our simple formulation, equations (7) and (3) imply that $d p_{t}^{E} / p_{t}^{E}=d x_{t} / x_{t}=\sigma_{x} d z_{t}$, so any stochastic variation in real ether values are driven by exogenous random changes in the convenience yield, thus by changes in $z_{t}$ which is correlated with $w_{t}$, which, in turn, captures stochastic inflation. Note that it is reasonable to assume that the convenience yield of holding ether depends negatively on inflation, which is another way of motivating $\rho<0$.

\subsection{Valuing two sides of the coin in relation to ether}

Creation of a stable currency comes down to materially decomposing units of ether into a stable (or solid) component $S$ and a volatile (or variable) component $V$. These components are created by locking up in escrow $\left(1+c_{t}\right) / p_{t}^{E}$ units of ether at time $t$, where $c$ indicates a collateral fraction. This process creates one unit of both $S$ and $V$ with market prices in real terms at each time $t$ of $p_{t}^{S}$ and $p_{t}^{V}$, respectively (nominal components are as in equation 1 ). At time $T$, the oracle announces the observed price level $P_{T}$ and given also $P_{T}^{E}$ this determines the values of both $S$ and $V$.

The stable component promises a real payoff of one (basket of) goods. The stable component may be used for transactions purposes but has an added advantage that it is truly risk free, i.e., constant in real terms. It has a convenience yield $y_{t}$ over the period until $T$. The locked up collateral is used to deliver the real payoff to $S$ and any remainder will go to $V$. In extreme cases, the real value of the collateral will have dropped too much for full satisfaction of the payoff for $S$. 
In these cases, the remainder goes to $S$ and the convenience yield of holding $S$ becomes zero. For simplicity we ignore fees. ${ }^{9}$ Thus,

$$
p_{t}^{S}=E_{t}\left\{\left(m_{T} / m_{t}\right)\left[y_{t} I\left(q_{t}^{E} p_{T}^{E}-1\right)+\operatorname{Min}\left(1, q_{t}^{E} p_{T}^{E}\right)\right]\right\}
$$

where $q_{t}^{E}=\left(1+c_{t}\right) / p_{t}^{E}$ is the quantity of locked-up ether and the indicator function $I(h)$ equals 1 if $h \geq 0$ and 0 otherwise. Equation (8) may be rewritten by understanding that the payoff of writing a put option is equal to $\operatorname{Min}\left(p_{T}-k, 0\right)$ (where $p_{T}$ is the price of the underlying asset at maturity and $k$ is the strike price) and in the Black-Scholes context has option price of $p_{t, T}^{\text {PUT }}\left(p_{t}, k\right)$. Thus, we can rewrite equation (8) as

$$
p_{t}^{S}=E_{t}\left[\left(\frac{m_{T}}{m_{t}}\right)\left[1+y_{t} I\left(q_{t}^{E} p_{T}^{E}-1\right)\right]\right]-p_{t, T}^{P U T}\left(1+c_{t}, 1\right) .
$$

The price of the put option is determined by the standard Black-Scholes formula for a European put option written on the ether holdings $q_{t}^{E} p_{T}^{E}$ and strike price equal to 1 .

The owner of component $V$ is the residual claimant and receives either the remaining initial collateral minus the promised real payment to component $S$, or nothing:

$$
p_{t}^{V}=E_{t}\left[\left(\frac{m_{T}}{m_{t}}\right) \operatorname{Max}\left(0, q_{t}^{E} p_{T}^{E}-1\right)\right]
$$

Writing it in terms of the put option price provides:

\footnotetext{
${ }^{9}$ Fees $f_{t}$ here are not essential for the functioning of the market. They may be included as a transfer from holders of $S$ to holders of $V$. However, an identical transfer may occur via the price mechanism, by changing $p_{t}^{S}$ versus $p_{t}^{V}$. The main use of fees would be to target a particular price for the stable coin. For instance, $p^{s}\left(f_{t}\right)=1$. However, this has only nominal advantages by facilitating the use of stable coins as units of account. For simplicity we set $f_{t}=0$ and focus instead on determination of the collateral fraction, $c_{t}$, which does have important impact on the market. In particular, it affects the incentives for creation of the dual coins as will follow from equation (17).
} 


$$
p_{t}^{V}=E_{t}\left[\left(\frac{m_{T}}{m_{t}}\right)\left(q_{t}^{E} p_{T}^{E}-1\right)\right]+p_{t, T}^{P U T}\left(1+c_{t}, 1\right)
$$

It follows that $V$ takes on the full risk of the price variation of ether. However, $S$ also takes on a risk related to writing a, presumably, far out-of-the-money put option.

From value additivity, the joint value of the two sides of the coin is from either equations (8) and (9) or equations ( $\left(8^{\prime}\right)$ and $\left(9^{\prime}\right)$ :

$$
p_{t}^{S}+p_{t}^{V}=E_{t}\left[\left(\frac{m_{T}}{m_{t}}\right)\left(\frac{\left(1+c_{t}\right) p_{T}^{E}}{p_{t}^{E}}+y_{t} I\left(q_{t}^{E} p_{T}^{E}-1\right)\right)\right]
$$

The combined value arises from two parts: the convenience yield provided by the stable coin and the present value of the locked up collateral, which depends on the real appreciation of ether.

\subsection{Solving for equilibrium outcomes}

We can now solve for the prices of $S$ and $V:{ }^{10}$

$$
\begin{aligned}
& p_{t}^{S}=\left[1+y_{t} N(d)\right] e^{-r(T-t)}-p_{t, T}^{P U T} . \\
& p_{t}^{V}=\left(1+c_{t}\right) e^{-\left(r-\rho \sigma_{x} \sigma_{m}\right)(T-t)}-e^{-r(T-t)}+p_{t, T}^{P U T} . \\
& p_{t, T}^{P U T}=e^{-r(T-t)} N(-d)-\left(1+c_{t}\right) N\left[-d-\sigma_{x}(T-t)^{1 / 2}\right], \\
& d=\left\{\ln \left(1+c_{t}\right)+(T-t)\left[r-\left(\sigma_{x}^{2} / 2\right)\right]\right\} / \sigma_{x}(T-t)^{1 / 2} .
\end{aligned}
$$

Here $N(d)$ represents the cumulative normal distribution at $d$. Equations (11) - (13) provide the prices of the stable and volatile coins as functions of variables yet to be determined: $y_{t}$ and $c_{t}$.

\footnotetext{
${ }^{10}$ To solve from (8') and (9') we use that $m_{T}=m_{t} e^{-\left[\left(\sigma_{m}^{2} / 2\right)+r\right](T-t)+\sigma_{m}\left(w_{T}-w_{t}\right)}$ and that $x_{T}=x_{t} e^{-\left(\sigma_{x}^{2} / 2\right)(T-t)+\sigma_{x}\left(z_{T}-z_{t}\right)}$ and that both as well as their product have a lognormal distribution. Also use equation (7) and the fact that $w$ and $z$ have instantaneous correlation of $\rho$.
} 
Equilibrium pricing (valuing all assets by the equilibrium stochastic discount factor) implies that the cost of creating the two coins is equal to the value sacrificed in their creation. Thus

$$
p_{t}^{S}+p_{t}^{V}=1+c_{t} .
$$

We find then that

$$
\left(1+c_{t}\right) e^{-\left(r-\rho \sigma_{x} \sigma_{m}\right)(T-t)}+y_{t} N(d) e^{-r(T-t)}=1+c_{t} .
$$

from equation (10) or by adding (11) and (12)). This equation says that the cost of locking up the real value $1+c_{t}$ in ether must equal the benefit which includes the present value of the convenience yield of holding the stable coin, when it is convertible, plus the present value of the initial quantity of ether released with a delay which discounts for the required return of holding ether containing the risk free rate plus the inflation risk premium. Solving equation (14') for $y_{t}$ yields:

$$
y_{t}=\frac{\left(1+c_{t}\right)\left[e^{r(T-t)}-e^{\rho \sigma_{x} \sigma_{m}(T-t)}\right]}{N\left[\left\{\ln \left(1+c_{t}\right)+(T-t)\left[r-\left(\sigma_{x}^{2} / 2\right)\right]\right\} / \sigma_{x}(T-t)^{1 / 2}\right]} .
$$

Given the term until oracle announcement, $T-t$, and required return parameters, the equilibrium convenience yield on the stable coin increases in the collateral fraction and increases in the inflation risk premium (with $\rho<0$ ): these raise the opportunity cost of locking up the ether, thus requiring the convenience yield to be higher.

To complete the model, consider that the (marginal) convenience yield of holding the stable coin should depend negatively on the quantity held. Thus,

$$
y_{t}=F\left(q_{t}^{S}\right), \quad d F\left(q_{t}^{S}\right) / d q_{t}^{S}<0 .
$$

From equation (15), 


$$
q_{t}^{S}=F^{-1}\left(\left(1+c_{t}\right)\left[e^{r(T-t)}-e^{\rho \sigma_{x} \sigma_{m}(T-t)}\right] / N(d)\right) .
$$

The quantity of stable coins provided in equilibrium depends negatively on the collateral fraction, $c_{t}$ and negatively on the inflation risk premium of ether, $-\rho \sigma_{m} \sigma_{x}$. More collateral makes the creation of the separate coins less attractive because the opportunity cost of doing so is the required return of the ether now locked up times $1+c_{t}$. A higher risk premium increases the hurdle for creation of separate coins because it raises the required return. For low quantities created, the benefit in terms of the marginal convenience yield from equation (15) is still high enough, but the critical quantity at which creation of the dual coins is no longer profitable is reached sooner.

The consumer surplus associated with the benefits of using the stable coin as a riskless and essentially frictionless medium of exchange is implicit in the demand function of equation (16). The consumer surplus is maximized when the quantity of stable coins held in equilibrium is maximized and occurs from equation (16) when the equilibrium convenience yield is minimized. The security fraction, $c_{t}$, of extra ether locked up to guarantee that the obligation to stable coin holders can be met may be chosen to maximize the consumer surplus. This choice defines the version of the stable coin that would survive in a competitive environment in which anyone may offer stable coins as described here but at differing security fractions. Thus, the equilibrium security fraction is the one maximizing the consumer surplus; minimizing the convenience yield. The first-order condition from setting $d y_{t} / d c_{t}=0$ based on equation (15) is:

$$
\sigma_{x}(T-t)^{1 / 2} N\left[d\left(c_{t}\right)\right]=n\left[d\left(c_{t}\right)\right],
$$

where $n()$ is the standard normal density and $d\left(c_{t}\right)$ is defined in equation (13). It can be shown straightforwardly that the equilibrium value of $c_{t}$ determined in equation (18) exists as the interior minimum based on equation (15) as long as the standard deviation of $x$ (the convenience yield of holding ether) is not too large. For $\sigma_{x}(T-t)^{1 / 2} \geq n[d(0)] / N[d(0)]$ the corner solution of $c_{t}=0$ will hold and there is no possibility for the stable coins as described here to be created in the market. 
The variance of the underlying asset return is important in affecting the attributes and quantity of the stable coin. For the regular (non-corner) solution it is simple to show that $d y_{t} / d \sigma_{x}>0$ implying less consumer surplus and a lower quantity provided of the stable coin if the variance is higher, and that $d c_{t} / d \sigma_{x}<0$, less collateral if the variance is higher, since reducing the probability of default by increasing the collateral is less effective. As we argue next the relevant component of $\sigma_{x}(T-t)^{1 / 2}$ relates to inflation risk exposure.

\subsection{The timing of oracle measurement and margin calls or shortfall}

From the prior analysis, the major obstacle in creating the stable currency is related to the value of the put option in equations (11) and (13): although out-of-the money, it prevents coin $S$ from being truly risk free. Increasing the collateral fraction $c_{t}$ takes the option further out of the money but at the expense of reducing the quantity created of the coins per equation (17).

It is possible to obtain a quantitative idea of the option value and the associated shortfall in meeting the obligation to keep the value of the stable coin at one real unit of the consumption basket. The following parameter values are relevant for numerical evaluation of the put option value in equation (13).

Given monthly oracle observations of the price of the underlying asset, we have that $T-t=1$ month. Further, $r=0.002$ (based on an annual real interest rate of 2.5\%), $c_{t}=0.5$ (a $50 \%$ additional collateral per unit of ether in escrow), $\sigma_{x}=0.49$ (standard deviation of the percentage change, the return, of the underlying asset - the number is the realized monthly return variance based on the last two years of data for ether, September 2015-August 2017). For these numbers we have that $d=0.59$. Then, $N(-d)=0.28, N\left[-d-\sigma_{x}(T-t)^{1 / 2}\right]=N(-1.08)=0.14$. So the put value is $p_{t, T}^{P U T}=0.2782-(1.5) 0.1408=0.067$, representing $6.7 \%$ of the real value of the basket of goods guaranteed by the stable coin. A larger collateral, say $c_{t}=1.0$, though implying a significant additional transactions cost, lowers the option value to $2.4 \%$.

The only answer to reducing the option value and associated risk of the stable coin is to reduce the variance and measurement interval, affecting $\sigma_{x}(T-t)^{1 / 2}$ in equation (13). The risk is related to variation in the value of ether relative to goods driven by $x_{t}$. From equation (1) it consists of 
two components: the variation relative to the dollar and the inflation component. It is relatively simple to protect the collateral against variations of dollar value as a close-to continuous market exists for pricing ether in dollar terms. The problem is possible shortfalls of the collateral relative to commitment at the time of (monthly) price level measurement. The challenge is to reduce $\sigma_{x}^{2}(T-t)$, where $T-t=1$ month for traditional measures of inflation and $\sigma_{x}^{2}$ represents the variance of inflation (reinterpreting the model to account continuously for the risk of fluctuations in the ether per dollar value).

In this scenario, we effectively set $\sigma_{x}$ equal to the monthly standard deviation of the inflation rate. From Table 1 we obtain $\sigma_{x}=0.0053$. Using the same parameter values as before we then find $d=76.9$ which implies that the put option price is effectively equal to zero. Thus, considering only inflation risk, $c_{t}=0.5$ is sufficiently high to drive the put option price to zero and avoid any chance of default. However, in competition the collateral will be lowered to around the minimum point for which the put option value is still negligible. To have an idea about a realistic value for the collateral that would emerge in this scenario, we specify an acceptable put option value and calculate what collateral fraction would be consistent with it.

Suppose that $p_{t, T}^{P U T}=0.0001$, which is one basis point per month for a unit of the stablecoin. Then for $\sigma_{x}=0.0053$ and $r=0.002$, equation (13) implies that $c_{t}=0.007$ or a collateral of $0.7 \%$. Any level of $c_{t}<0.007$ would trigger a margin call. Even at this relatively low level of collateral, competitive issuance of stable coins would favor less collateral or lower put option prices.

A solution is to base margin calls for the collateral on predicted inflation, which may be generated using continuously observable coincident indicators. This approach leaves a reduced standard deviation $\left(1-R^{2}\right) \sigma_{x}^{2}$, where $R^{2}$ is the R-squared in the predictive regression for inflation, at the time of the oracle announcement at time $T$ revealing the realized price level. Clearly, the value of the put option and the associated average shortfall at time $T$ should be reduced as much as possible to provide the most efficient market mechanism. Such reduction is essential for the viability of the stable currency, because entry into the market of cryptocurrencies via initial coin offerings has low friction. The theory of “contestable markets” argues that the market's mechanism design should produce the best available alternative, even in absence of direct competition based on the threat of entry by potential competitors (Baumol, 1982). 
In the following empirical exercise, we consider how non-manipulable on-line indicators available at high frequency may be utilized to lower the put option value affecting the risk of the stable coins by reducing inflation risk at the time of oracle announcements.

\section{Empirical models for measured inflation targets}

For our empirical analysis, we focus on the issue of forecasting a representative inflation target using contemporaneous data, where the contemporaneous exogenous predictors are also available in higher frequency. Specifically, we will build an estimation model from monthly data—when the underlying inflation target is observable - that can then be updated in market time using the higher frequency exogenous variables.

To reiterate our previous discussions, we are essentially trying to create a daily measure of inflation based on the prior time-series of monthly inflation observations supplemented with predictive variables that are traded in market time in broad and deep markets that cannot be easily manipulated. Such a model, to the extent that it has predictive ability, spans the pricing gap created by anchoring a continuously traded currency to a monthly target. That is, an instantaneous measure of inflation can be estimated based on the past time series of the target along with contemporaneous variables that are known to correlate with inflation.

For these experiments we set aside the global perspective from the broader discussion of currency design and simply focus on the issue of forecasting inflation as a time-series using the United States Consumer Price Index (CPI) as a proxy for inflation. We discuss extending these results to the global realm in the conclusion. Also, note that because we are focusing on contemporaneous prediction, we can ignore the lag between the release date of the CPI and its month of measure.

The focus of creating such a series is to dampen large unexpected jumps in the price level. These jumps could lead to shortfalls at the time of the oracle announcement. The possibility of shortfalls is responsible for the put option values that detract from the stability of the stablecoin. Hence, our model selection process will emphasize including a sufficient span of variables that will be robust to very infrequent shocks that might occur. For example, Hooker (2002) finds that oil prices had a significant effect on inflation from 1962-1980, but not from 1981-2000. Thus, in our models we include an energy measure as something that over a long interval has produced inflation shocks even though in a given period the impact may not be important. 


\subsection{Model structure}

Our models will consist of the inflation data along with a group of additional independent variables intended to predict contemporaneous inflation. Because we want these independent variables to be traded in market time and have market depth, we will use well-established Exchange Traded Funds (ETFs) as the building blocks for the forecasting model. For the variables of interest, the time series is limited by data availability to 2004-2016. We use a rolling regression of 48-monthly observations to predict the next month's out-of-sample inflation measure. To initially parameterize the autoregressive component of the models and identify a parameter value in the Lasso regressions we use the pre-sample period observations of inflation from January, 1926 to December, 2003. We then measure the predictive accuracy by using rolling regressions over the 2004-2016 monthly time series. Thus, for example, after parameterizing the model using the presample data, the first forecast observation will be based on models estimated using monthly data from January, 2004 to December, 2007, which are then used to predict the January, 2013 value. This process repeats through the final forecast period of December, 2016 (108 months).

\subsection{The time-series of inflation}

Inflation has been measured by the Bureau of Labor statistics since 1913. Given inflation's role as a central macro-economic variable, econometricians have examined extensively its predictive properties. Ang et al. (2007) provide one of the most exhaustive and most recent discussions of predicting inflation along with an extensive review of prior research on the topic. Although we will use many of the results of Ang et al. as a basis for our model development, it is important to note that our context is very different. Past papers focus on predicting a next-period observation of inflation using its historical values along with observations of related economic variables (e.g., GDP, unemployment, interest rates) measured in the prior period. In our case, we want to predict a given time-series observation of inflation using contemporaneous variables in order to provide an up-dated proxy measure using real-time market observations of the predictive variables. 


\subsubsection{Descriptive statistics}

We begin by characterizing the inflation time series. As noted in Ang et al. (2007), the substantial literature testing the time-series stationarity of inflation has not reached a consensus. Consistent with their paper, we will focus on the percentage change in the CPI measure. Specifically, we use the monthly CPI_Ret from the Center for Research in Security Prices (CRSP), which is the Consumer Price Index for all urban consumers, not seasonally adjusted (CPI-U NSA) produced by the U.S. Department of Labor, Bureau of Labor Statistics.

Descriptive statistics for the full 1926-2016 time-series of CPI_Ret appear in Table 1. From Panel A, the average value of CPI_Ret for the monthly data of $0.24 \%$ is consistent with an annual historical average of about $2.9 \%$. The standard deviation of $0.53 \%$ reflects the high volatility of the series over its long history. The skewness of the time series is modestly positive at 1.04, which would be expected given that negative measures of notable magnitude are extremely unlikely. The kurtosis statistic (where a normal distribution would have kurtosis of 3), clearly documents the capacity of inflation to shift from stable to extreme values. ${ }^{11}$ Figure 2 provides a histogram of CPI_Ret with a normal distribution overlay that highlights the bipolar behavior of the time series, with a thick density of percentage changes registering between 0 and 1 percent and much more density in the tails than a normal.

Panel B of Table 1 provides a simple summary of the highest inflationary periods by date, both monthly and annually. The differences between the periods highlighted by the monthly versus annual data show the impact of the occasional spurts of persistence in CPI_Ret. For example, although there is no single monthly observation from the post-1940's in the list until the tenth item, six of the ten highest annual inflationary periods occur in the 1970's and 1980's (1973-1974, 19781981).

Deflation we know is a less frequent experience, with only about $15 \%$ of the monthly observations, and only $11 \%$ of the annual observations being negative. The three highest levels of deflation over calendar years were during the depression era, with values of $-5.8 \%,-8.2 \%,-8.4 \%$ for the years 1930, 1931, and 1932, respectively. The highest monthly value, $-2.05 \%$ in 1932, was also from this era. The persistent deflation of the depression, when more than a quarter of the banks failed and the stock of money fell by almost one third, is well documented in Friedman and

\footnotetext{
${ }^{11}$ The high value of kurtosis does not specifically document either a large or small number of tail observations relative to a normal distribution (see Cox (2010)).
} 
Schwartz (1963). The only monthly values not from the pre-1940 era that are also in the twenty highest deflationary tally are all from 2008, with the second highest historical calendar monthly value of -1.92\% occurring in November, 2008.

\subsubsection{Autoregressive properties of the time series}

Our predictive model will include both lagged values for CPI_Ret in addition to the other contemporaneously measured variables. To establish the most appropriate format for the autoregressive component of the model we will exploit the longer time-series of inflation observations available, using the 1926-2003 period for the pre-estimation experiments.

The first four lags of CPI_Ret all have correlations with the current period value of greater than 0.35. Figure 3 presents partial autocorrelations for CPI_Ret, which control for the effect of shorter period lags. Although the partials drop quickly from the initial value of 0.48 to values between 0.15 and 0.20 , the significance of the lags supports the use of a model with four lags. To confirm this initial choice we calculate the Schwarz Bayesian Information Criterion (SBIC) for zero to eight lags. The SBIC value is minimized at four lags; however, we also note that the Akaike Information Criterion statistic would extend this recommendation to eight lags. In the interest of parsimony, we choose four.

Given the importance of the autoregressive properties of the CPI_Ret time series, and having established the lag dimensionality using the pre-sample data, we plot in Figure 4 the 48 -month rolling autocorrelations for the first four lags across the entire sample. The ranges for lags one through four over the entire sample period are, respectively, [0.72, -0.45], [0.59, -0.33], [0.49, $0.43]$, and [0.49, -0.29]. These results highlight the persistence and magnitude of the lag structure while also revealing its dynamic nature. In the sample period we are examining, using the preestablished four-lag model, the lagged correlations are much lower than their pre-1980 averages.

\subsection{Coincident predictive variables}

In order to produce intra-period estimates of inflation we choose economic attributes consistent with prior literature with a focus on instruments that are actively traded. With one exception, we will use actively traded Exchange Traded Funds (ETFs) as the variables appended to the basic autoregressive model. The exception is based on Maker's proposal in their white paper to link to 
the International Monetary Fund's Special Drawing Rights (SDRs). ${ }^{12}$ These exchange rates are available on a daily basis, and they have a sufficient monthly time series available for the estimation process. We use the percentage change in the SDR per unit of U.S. \$1 as the measure we label $S D R$.

Table 2 presents the remaining ETF-based coincident indicators we select, in addition to the SDRs. All ETF data is taken from the Center for Research in Security Prices (CRSP). Given the strong arbitrage link between these ETFs and their underlying assets in addition to their market depth, it is reasonable to take them as a proxy that would be difficult to manipulate to any significant degree. All but one of the ETFs has daily trading volume greater than $\$ 10$ billion.

The Treasury Inflation Protection ETF (TIP) is selected as an instrument that should, prima facie, be linked to inflation. Ang (2012) and others note, however, that the correlation between TIPs and inflation is not what might be expected due to the specifics of the TIP contract and other market-related variables.

The SHY ETF, representing the return on 1-3 year treasuries, captures the impact of short-term interest rates. A gold ETF (GLD) is included due to the rich folklore linking it to inflation, although Ang (2012) reports that it is a surprisingly poor inflation hedge over his 1952-2012 sample. Oil $(D B O)$ has a similar strong anecdotal link to inflation that has mixed empirical support (see Ang (2012)). ${ }^{13}$ Consumer discretionary stocks are included with the $X L Y$ ETF, which provides a broad stock market measure that focuses on one aspect of inflation not explicitly proxied by the other variables.

\subsection{Sample correlations}

Before presenting the regression results, in Table 3 we first consider the simple correlations between the variables of interest for the sample period January, 2004 to December, 2016. Although

\footnotetext{
12 See https://github.com/makerdao/docs/blob/master/Dai.md.

${ }^{13}$ Interestingly, as Ang (2012) notes, in perfect markets with no extraction costs commodities should have no correlation with inflation.
} 
the one-period lag for CPI_Ret produces a correlation of about 0.53 , as noted before, the two to four month lags during this period appear much less important relative to their historical levels.

We include SDRs in the analysis because Maker, one of the blockchain-related organizations attempting to build a "stable" currency, will "keep its market stable relative to SDR." ${ }^{14}$ SDRs represent an amalgamation of currency exchange rates. ${ }^{15}$ Prior to the 1971 Bretton Woods agreement, many economists assumed that with floating rates, SDRs would reflect purchasing power parity. ${ }^{16}$ The pre-supposed relation between inflation and currency-related economic variables did not turn out as expected with floating exchange rates and in practice is much more complex. ${ }^{17}$ Even if this simple relation held in practice, note that changes in SDRs reflect changes in relative inflation rates across the various countries. If all of the representative countries have the same level of inflation, the SDR value will not change. Thus, in terms of an ideal currency that is denominated in purchasing power, an SDR benchmark will not produce the desired result. In our sample, the correlation between $C P I$ Ret and SDR is -0.19 . Obviously, we are measuring against only one component of the currency basket, but the correlation is not of the magnitude that casual interpretation might predict.

The TIP correlation is only 0.036, which might be explained by the factors discussed in Ang (2012) but, in this case, is also impacted by the contract's defining inflation in terms of lagged observations. Of the ETF variables only $D B O$, the oil ETF, shows a notably high bivariate correlation of 0.467 with CPI_Ret. The correlations within the coincident variables are in some cases sufficiently high, especially in a limited sample, to raise some concerns about multicollinearity, which we address in our model selection process.

\subsection{Regression Results}

We examine the forecastability of CPI_Ret using monthly observations from January, 2004 through December, 2016 in the context of four models. For the regression-based models, we use a

\footnotetext{
${ }^{14}$ See makerdao.com.

${ }^{15}$ The basket of currencies in the SDR has varied over time, beginning with a combination of the Deutsche mark, French franc, Japanese yen, U.K. pound sterling, and U.S. dollar. The euro replaced the mark and franc in 1999, and the Chinese Yuan was added in October of 2016. The current weights for the dollar, euro, renminbi, yen, and pound are $41.73 \%$, 30.93\%, 10.92\%, 8.33\% and 9.09\%.

${ }^{16}$ See Ghosh et al. (2014) for an example advocating Milton Friedman’s pre-Bretton Woods arguments.

${ }^{17}$ See Burstein and Gopinath (2014) or Froot and Rogoff (1995) for a discussion of these issues.
} 
rolling time series where four years of past monthly data are used to predict the subsequent month's percentage change in inflation. The forecast accuracy of the models is measured using the rootmean-squared-error (RMSE) based on the resulting 108 one-month ahead forecasts.

Model 1: Naïve - As is typical in judging forecast accuracy, especially with time-series having some degree of autocorrelation, we use a simple naïve model of the prior period's value as a base case.

Model 2: AutoC4 - We know from Ang et al. (2007) that beyond economic surveys a simple autoregressive model produces some of the best predictive models, at least in their case based on historical data (versus our attempt to fold in contemporaneous measures).

Model 3: RegAll - A simple ordinary least squares (OLS) model with the coincident variables-SDR, TIP, SHY, GLD, $D B O, X L Y$-appended to the autoregressive model with four lags.

Model 4: Lasso - Lasso regression is a penalized regression method that augments the usual minimization of squared residuals in OLS with a penalty equal to a weight (typically labeled lambda) times the sum of the absolute value of the estimated coefficients. ${ }^{18}$ The Lasso approach has significant appeal in the context of our models. Because it is likely that the sensitivities of inflation to its various components vary through time, we prefer a model that errs on the side of overspecification. Lasso allows us to be generous in terms of the number of variables we include in the model as the penalty function will, for a given estimation period, tend to push less relevant variable coefficients to zero. The penalty weight is somewhat arbitrary and we have a very limited sample period. Thus, we use the AutoC4 model estimated on the out-of-sample January, 1926 through December, 2003 period to determine the value of lambda that minimizes the RMSE of the predictions. We consider values from .0001 to 0.5. The function has a clear minimum at lambda $=0.005$ and this is the value we will use to weight the penalty function in our Lasso model.

The RMSE for each model is presented relative to the Naïve model-thus, lower values indicate better predictions - in Table 4. To provide some notion of the magnitude of the prediction errors, recall from Table 1 that the average CPI_Ret value is $0.24 \%$ with a two-standard deviation range of about plus or minus $1 \%$. The average absolute error for the Naïve model is about $0.29 \%$. The comparative results in Table 4 suggest that the simple autoregressive model clearly has

\footnotetext{
${ }^{18}$ Hastie, Tibshirani and Wainwright (2015) provide a detailed discussion of Lasso and its extensions. A basic explanation also can be found on a website authored by Tibshirani at statweb.stanford.edu/ tibs/lasso.html.
} 
predictive content, however in the context of our currency design scenario this is not particularly useful because it does not allow us to update the estimates in market time. ${ }^{19}$ As previously discussed, the RegAll model is presumably over-specified and contains independent variables that in some cases have relatively high correlations. Thus, it is not wholly unexpected that the full regression, which embeds the AutoC4 model, is actually less accurate in predicting out-of-sample than the AutoC4 model, with an RMSE of 0.980 for the full regression compared to 0.956 for the autoregressive model. However, when we extend the basic OLS model to the Lasso model, the RMSE drops to 0.903 . This result suggests that there is some predictive value in using coincident variables to provide estimates of inflation that can be updated in market time.

Within the Lasso model framework, it is of interest to identify which variables have non-zero coefficient estimates across the various periods. Table 5 presents the percent of cases for the 108 regressions where each coefficient estimate was non-zero. (Note that because of the penalty function, in no case are the estimates very near zero.) Interestingly the second lag in the autoregressive component dominates the others in terms of its persistence across the rolling time frames. Of the coincident indicators, the gold ETF seems most relevant for the sample period, producing a non-zero coefficient in $78.7 \%$ of the predictions. The interest rate surrogate provided by $S H Y$ (the 1-3 treasury) is least prevalent and is non-zero in only $27.8 \%$ of the cases.

Our theoretical results emphasize the importance of the R2 of a predictive model in reducing the oracle's volatility. If we use the squared correlation of the predicted and actual values for the 108 Lasso model results as a pseudo-R2, we can reduce the variance by about 30\%. Thus, it would appear that a model can be estimated from historical monthly data and updated with daily observations of coincident indicators that will lower the option costs and, in turn, provide a more efficient market mechanism for the currency.

The $R^{2}$ of $30 \%$ implies that the standard deviation $\sigma_{x}$ of 0.0053 for inflation risk without forecasting is reduced to $\sqrt{\left(1-R^{2}\right) \sigma_{x}^{2}}=0.0044$ using the Lasso approach to forecast. The implication is that, taking an acceptable value for the put option of 1 basis point per month, the required collateral is now reduced from $0.7 \%$ to $0.5 \%$.

\footnotetext{
${ }^{19}$ Obviously, you could provide some sort of interpolation on a daily basis for the next month's forecast of inflation, but this does not add any contemporaneous information to the forecast.
} 


\section{Conclusions}

Until recently, the notion of an optimally designed global currency was an interesting abstraction that saw little chance of becoming a reality in a world where only governments, who are unlikely to give up the budgetary flexibility of seigniorage, can issue fiat money. With the recent evolution of distributed-trust technologies, popularized by Bitcoin, essentially anyone can produce a currency. Many of the recent internet coin offerings (ICOs) related to currency design focus on the stability of their offering relative to the dollar, but a properly designed stabilizing feature can take a significant step toward an optimal global currency. The concept of optimal design for a global currency is relatively simple, i.e., a currency linked to a representative consumption basket.

Linking a currency to a weighted combination of inflation for major countries would be a significant step in moving toward this ideal currency. One of the important limitations of this process is attributable to the risk created by a measure that is only produced on an infrequent basis for a currency that is trading in real time.

We contribute to this area by first identifying the pricing of the currency relative to a given oracle. We show that the value of the stable currency due to the oracle not being continuous is the value of the consumption basket minus a put option, the cost of which is increased by the trading fees and the collateral percentage as well as by the variance of the unpredictable inflation component. The variance of the oracle value will increase with an increasing measurement interval, with both of these dynamics increasing the option cost. Thus, designing a method that will proxy the inflation measure in market time is important in potentially reducing this cost.

We provide some experimental evidence on the potential for creating a measure of inflation that updates in market time. The initial results suggest this is an approach that might contribute to reducing the costs of stabilizing a currency.

These are first steps in addressing some of the major hurdles in creating a global digital currency. Our empirical results are constrained by the limited time series of observable market variables and the relatively low and stable level of inflation of the past decade.

Nontrivial details and outstanding issues remain. A blockchain-based design mechanism in this case must rely on signals from outside the system for the values of economic measures. The purely algorithmic and trusted environment of the blockchain then requires a trusted source for these numbers. In some countries, the government's production of economic measures such as inflation are not considered outside the realm of manipulation. Country-specific tax policies will 
impact the net value of a currency denominated in real terms. Additionally, as is well documented in the literature on measuring inflation, the real impact of inflation is to some extent idiosyncratic for each individual. One can imagine scenarios where consumption bundles are pre-defined and are priced in real time from online sources, creating a government-agnostic measurement mechanism. Given sufficient market depth for the currency, multiple consumption bundles might be defined that better approximate the inflation exposure of different socio-economic classes (e.g., a retirement class, a country-specific class, etc.). Much like the promise of the internet in the 1990's, it will likely take decades to move closer to the reality of a global currency. 


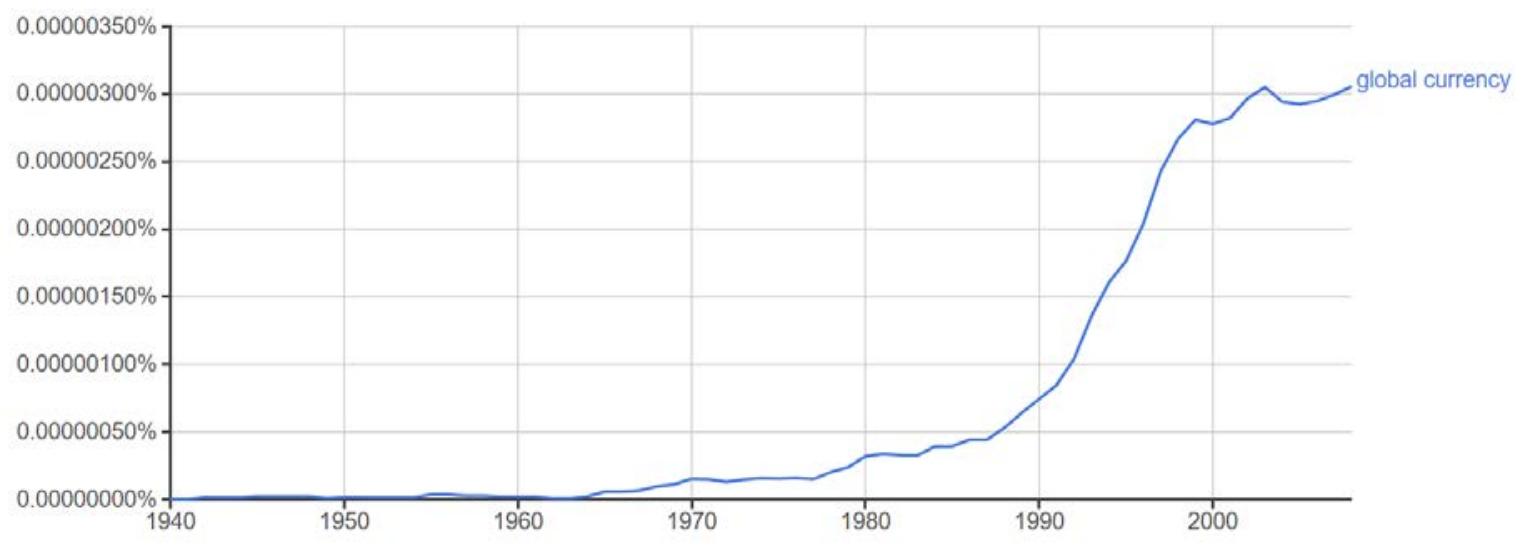

Fig. 1. “global currency” n-gram frequency. Source: Google ngram viewer. 


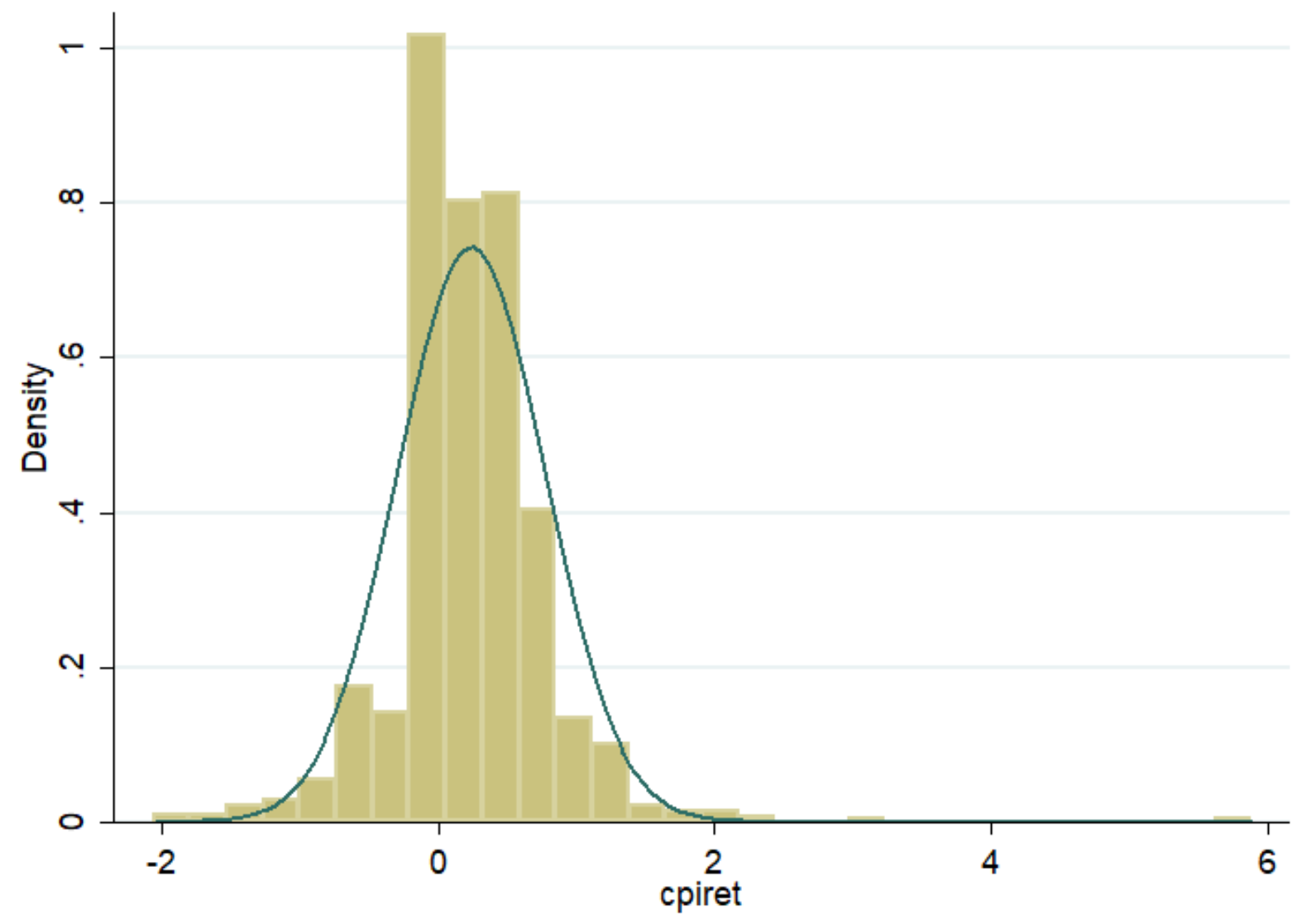

Fig. 2. Histogram for the January, 1926 to December, 2016 CPI_Ret time series. A normal density plot is overlaid. 


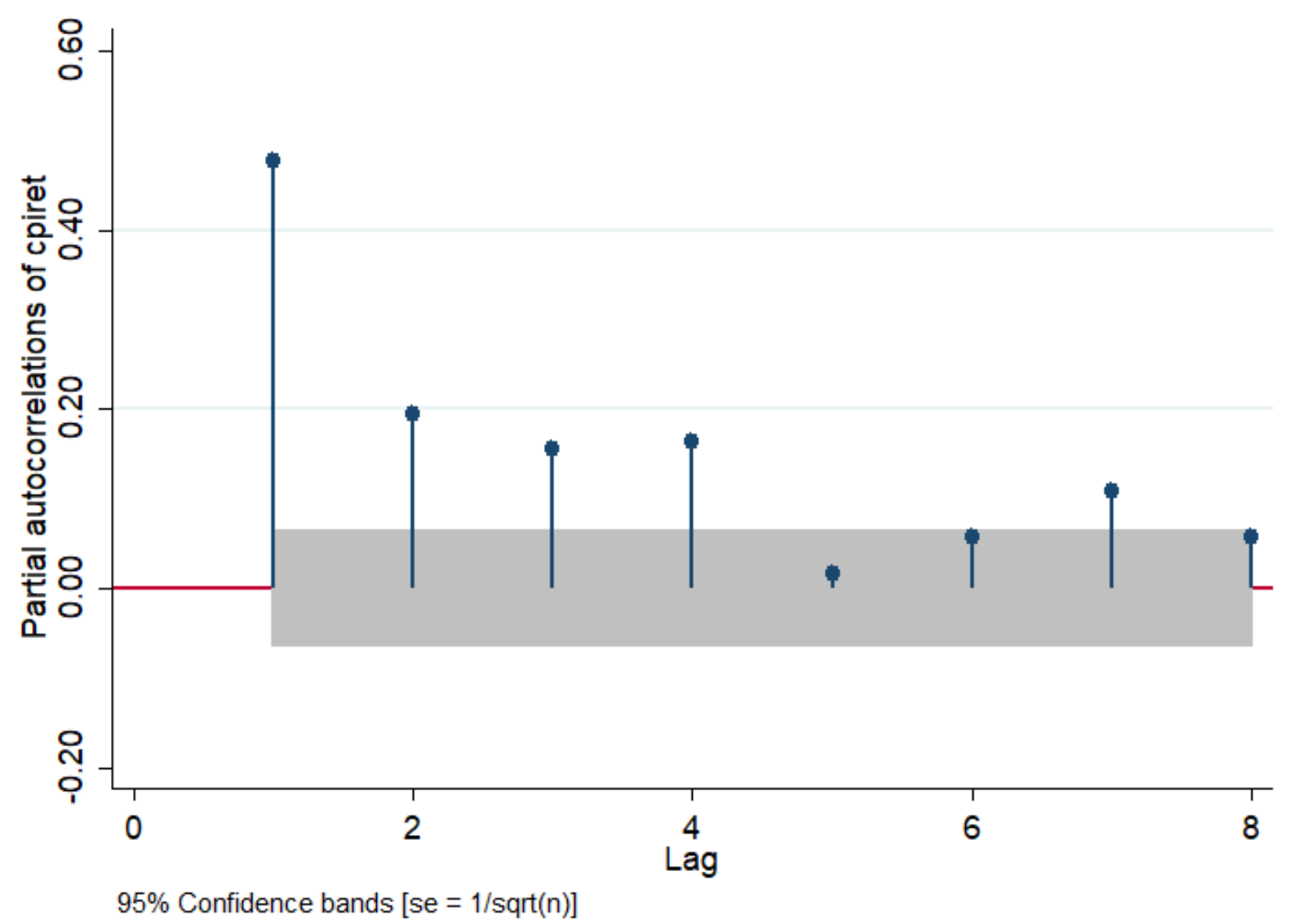

Fig. 3. Partial autocorrelations of CPI_Ret for the pre-estimation period sample of January, 1926 to December, 2003. 


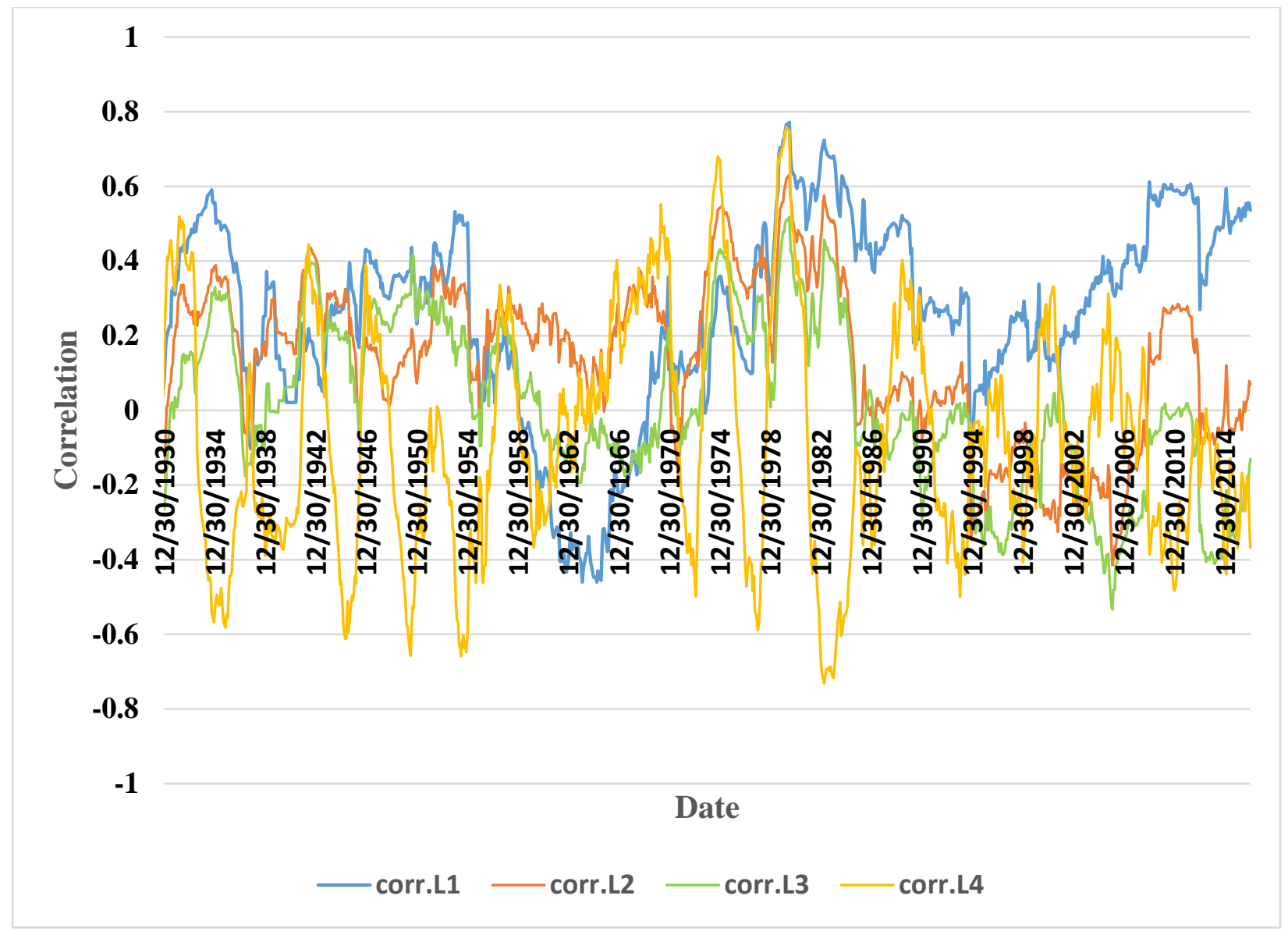

Fig. 4. Lagged correlations (1-4) for CPI_Ret using a 48-month window over the January, 1926 to December, 2016 period. 


\section{Table 1}

Descriptive statistics for CPI_Ret.

The table reports descriptive statistics for the full monthly time series of January, 1926 to December, $2016(\mathrm{~N}=1,092)$ for the percentage change in the Consumer Price Index for all urban consumers, not seasonally adjusted.

\begin{tabular}{|c|c|c|c|}
\hline \multicolumn{4}{|c|}{ Panel A: Summary statistics } \\
\hline Mean & $0.24 \%$ & Skewness & 1.044 \\
\hline Std Dev & $0.53 \%$ & Kurtosis & 16.36 \\
\hline \multicolumn{4}{|c|}{ Panel B: Dates for the 10 Highest Values of CPI_Ret } \\
\hline \multicolumn{2}{|c|}{ Monthly } & \multicolumn{2}{|c|}{ Annual } \\
\hline Date & Value & Date & Value \\
\hline 194607 & $5.88 \%$ & 1946 & $18.13 \%$ \\
\hline 193307 & $3.15 \%$ & 1979 & $12.30 \%$ \\
\hline 194611 & $2.40 \%$ & 1974 & $11.37 \%$ \\
\hline 194709 & $2.22 \%$ & 1980 & $10.93 \%$ \\
\hline 193909 & $2.17 \%$ & 1941 & $9.93 \%$ \\
\hline 194106 & $2.08 \%$ & 1947 & $8.84 \%$ \\
\hline 194608 & $2.02 \%$ & 1973 & $8.45 \%$ \\
\hline 194610 & $1.96 \%$ & 1978 & $8.32 \%$ \\
\hline 194703 & $1.86 \%$ & 1981 & $8.05 \%$ \\
\hline 197308 & $1.81 \%$ & 1942 & $7.64 \%$ \\
\hline
\end{tabular}




\section{Table 2}

Description of coincident variables. To extend the sample beginning date back to January, 2004 the time series for gold and oil ETFs are augmented using the percentage change in the prices of the underlying commodities.

\begin{tabular}{|c|c|c|c|c|c|}
\hline Variable & BegDat & Permno & Name & $\begin{array}{l}\text { Net } \\
\text { Asset } \\
\text { Value }\end{array}$ & $\begin{array}{l}\text { Average Daily } \\
\text { Trading Volume } \\
\text { Dec. } 2016 \text { (\$mil.) }\end{array}$ \\
\hline$S D R$ & 19810105 & n.a. & IMF Special Drawing Rights ( $\$ 1=x$ SDR) & n.a. & \\
\hline TIP & 20031205 & 89959 & iShares TIPS Bond & $\$ 24.18 \mathrm{~B}$ & $\$ 226$ \\
\hline SHY & 20020726 & 89470 & iShares 1-3 Year Treasury Bond & $\$ 11 B$ & $\$ 133$ \\
\hline GLD & 20041118 & 90448 & SPDR Gold Shares & $\$ 34.5 B$ & $\$ 835$ \\
\hline$D B O$ & 20070105 & 91713 & PowerShares DB Oil ETF & $\$ 390 M$ & $\$ 5$ \\
\hline$X L Y$ & 19981222 & 86453 & Consumer Discretionary SPDR & $\$ 12.8 \mathrm{~B}$ & $\$ 447$ \\
\hline
\end{tabular}




\section{Table 3}

Variable correlations for the monthly data January, 2004 to December, 2016.

\begin{tabular}{|c|c|c|c|c|c|c|c|c|c|c|c|}
\hline & CPI_Ret & lag_1 & lag_2 & lag_3 & lag_4 & $S D R$ & TIP & SHR & GLD & $D B O$ & $X L Y$ \\
\hline CPI_Ret & 1.000 & & & & & & & & & & \\
\hline lag_1 & 0.529 & 1.000 & & & & & & & & & \\
\hline lag_2 & 0.099 & 0.530 & 1.000 & & & & & & & & \\
\hline lag_3 & -0.124 & 0.102 & 0.532 & 1.000 & & & & & & & \\
\hline lag_4 & -0.163 & -0.125 & 0.100 & 0.530 & 1.000 & & & & & & \\
\hline$S D R$ & -0.192 & -0.007 & -0.022 & -0.028 & 0.084 & 1.000 & & & & & \\
\hline TIP & 0.036 & -0.058 & 0.059 & -0.075 & -0.128 & -0.420 & 1.000 & & & & \\
\hline SHY & -0.171 & -0.118 & 0.090 & 0.121 & 0.155 & -0.170 & 0.462 & 1.000 & & & \\
\hline GLD & 0.045 & -0.140 & -0.155 & -0.010 & -0.052 & -0.402 & 0.420 & 0.240 & 1.000 & & \\
\hline$D B O$ & 0.467 & 0.201 & 0.041 & 0.048 & -0.066 & -0.411 & 0.154 & -0.163 & 0.222 & 1.000 & \\
\hline$X L Y$ & -0.004 & 0.051 & 0.095 & -0.043 & -0.253 & -0.290 & 0.125 & -0.269 & -0.033 & 0.215 & 1.000 \\
\hline
\end{tabular}




\section{Table 4}

Results of the prediction models. The root-mean-square-error (RMSE) for each model is expressed relative to the Naïve model.

\begin{tabular}{lllll}
\hline Model: & Naïve & AutoC4 & RegAll & Lasso \\
\hline Relative RMSE: & 1.000 & 0.956 & 0.980 & 0.903
\end{tabular}


Table 5

Percent of cases where Lasso parameter estimates are nonzero for each independent variable based on 108 estimates.

\begin{tabular}{lc}
\hline Variable & $\begin{array}{c}\text { \% of non-zero } \\
\text { estimates }\end{array}$ \\
\hline lag_1 & $25.9 \%$ \\
lag_2 & $95.4 \%$ \\
lag_3 & $18.5 \%$ \\
lag_4 & $65.7 \%$ \\
SDR & $39.8 \%$ \\
TIP & $52.8 \%$ \\
SHY & $27.8 \%$ \\
GLD & $78.7 \%$ \\
DBO & $37.0 \%$
\end{tabular}




\section{References}

Ang, Andrew, 2012, 'Real’ assets, Columbia Business School Research Paper No. 12-60.

Ang, Andrew, Geert Bekaert, and Min Wei, 2007, Do macro variables, asset markets, or surveys forecast inflation better?, Journal of Monetary Economics 54, 1163-1212.

Ang, Andrew, Asset Management: A Systematic Approach to Factor Investing, 2014, Oxford University Press, New York, NY.

Baumol, William J., 1982, “Contestable markets: an uprising in the theory of industry structure," American Economic Review 72, 1-15.

Burstein, Ariel, and Gita Gopinath, 2014, International prices and exchange rates, Handbook of International Economics 4, 391-451.

Cong, Lin William, and Zhiguo He, 2017, Blockchain Disruption and Smart Contracts, SSRN: https://ssrn.com/abstract=2985764.

Cox, Nicholas J., 2010, Speaking Stata: The limits of sample skewness and kurtosis, The Stata Journal 10:3, 482-495.

Davies, Glynn, 2002. A History of Money: From Ancient Times to the Present Day, University of Wales Press, 3rd Edition.

Friedman, Milton and Anna Jacobson Schwartz, 1963, National Bureau of Economic Research, Princeton University Press, Princeton.

Froot, Kenneth A. and Kenneth Rogoff, 1995, Perspectives on PPP and long-run exchange rates, G. Grossman, K. Rogoff (Eds.), Handbook of International Economics 3.

Ghosh, Atish R., Mahvash S. Qureshi, and Charalambos G. Tsangarides, 2014, Friedman redux: External adjustment and exchange rate flexibility, IMF Working Paper.

Gorton, Gary, 2017, The history and economics of safe assets, Annual Review of Economics 9, https://doi.org/10.1146/annurev-economics-033017-125810.

Harvey, Campbell R, 2016, Cryptofinance, SSRN: http://ssrn.com/abstract=2438299.

Hastie, Trevor, Robert Tibshirani, and Martin Wainwright, 2015, Statistical Learning with Sparsity: The Lasso and Generalizations, Taylor \& Francis Group, Boca Raton, FL.

Hooker, Mark, 2002, Are oil shocks inflationary? Asymmetric and nonlinear specifications versus changes in regime, Journal of Money, Credit, and Banking 34:2, 540-561.

Huberman, Gur, Jacob D. Leshno, and Ciamac Moallemi, 2017, Monopoly without a monopolist: An economic analysis of the bitcoin payment system, working paper, Columbia Business School. 
Rogoff, Kenneth, 2001, Why not a global currency?, The American Economic Review 91, 243247.

Sargent, Thomas J. and Francois R. Velde, 2002, The big problem of small change. Princeton University Press, Princeton: NJ.

Stock, J.H., and M.W. Watson, 2003, Forecasting output and inflation: The role of asset prices, Journal of Economic Literature 41, 788-829.

Turing, Alan Mathison, 1937, On computable numbers, with an application to the Entscheidungsproblem, Proceedings of the London Mathematical Society 2, 230-265.

Yermack, David, 2017, Corporate Governance and Blockchains, Review of Finance, doi:10.1093/for/rfw074. 